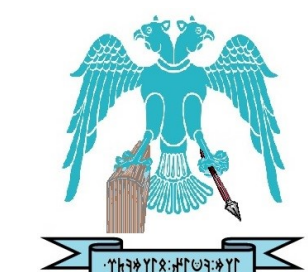

Journal of Energy Systems

$2020,4(4)$

\title{
Voltage regulation of soft switched interleaved boost converter using fuzzy proportional integral controller
}

\author{
PremkumarKamaraj (iD \\ Rajalakshmi Engineering College, Chennai, Tamilnadu,prem.kamaraj@gmail.com \\ ThamizhselvanThamizharasu (D) \\ Rajalakshmi Engineering College, Chennai, tamilselvan84@gmail.com \\ M. Vishnu Priya \\ Saveetha School Engineering, Chennai, vish0790@gmail.com
}

\begin{abstract}
This paper discusses about a fuzzy PI controlled three-stage soft switched interleaved boost converter with improved switching method. The proposed fuzzy PI controller has been compared with theproportional integral controller. The proposed fuzzy PI controlled soft switched interleaved boost converter model has been developed and tested in MATLAB/SIMULINK environment. Performance of the designed controller is tested under different loading constraints and step change for reference voltage conditions. Four performance parameters are taken consideration for the analyses such as integral of time multiplied absolute error, integral of squared error, integral of absolute error, and settling time for an effective comparison. From the simulation results, fuzzy PI controlled soft switched interleaved boost controller has exhibited better performance than PI controlled soft switched interleaved boost converter. Experimental verification has also been conducted to check the effectiveness of the proposed fuzzy PI controlled soft switched interleaved boost converter.
\end{abstract}

Keywords: Fuzzy PI controller, Interleaved boost converter, PI controller, Soft switching

Cite this paper as:

Kamaraj, P.,Thamizharasu, T., \&Priya, M.V.,Voltage regulation of soft switched interleaved boost converter using fuzzy proportional integral controller. Journal of Energy Systems 2020, 4(4), 145-160, DOI: $10.30521 /$ jes.762506 


\section{INTRODUCTION}

The boost converter is a most accepted topology for electrical energy conversion system and it also serves as DC voltage regulator due to its merits of simplicity and high performance, however it has some disadvantages such as switching loss increases due to the increase in the switching frequency [1]. The disadvantage of the boost converter is overcome by the interleaving method of boost converter and it will increase the switching frequency without increasing the switching losses, thereby increasing in the energy density without compromising efficiency [2]. Interleaving technique reduces the filter capacitor size, reduces the output current ripples with a function of duty cycle. To reduce the switching losses, the circuits consist of auxiliary circuits, which completely decrease the conduction loss by turning ON and OFF the power switches under the zero current switching and zero voltage switching condition correspondingly [3]. In addition, the voltage regulation is the most important thing in the soft switched interleaved boost converter. Normally, the voltage regulation of converter is achieved by Proportional integral (PI) controller in a closed loop manner [4]. The proportional controller have simple structure and it is implemented easily by using a microcontroller. But it also hassome demerits such as,

1) constant parameter of the PI controller [5],

2) manual tuning with changes in operating conditions of the system which is under control [5].

PI controller has been optimized by various optimization techniques such as the particle swarm optimization, genetic algorithm, bat algorithm, but these algorithms tune the parameter of the PI controller in offline mode [6]. The major drawback of offline mode is that there are many iterations and trials have to be performed for obtaining the optimal solution and also this is a time consuming process [7]. In order to conquer the drawback of offline mode, in the present paper, online tuning or automatic tuning of a PI controller is proposed by using the fuzzy controller. The fuzzy controller automatically tunes the parameter of the PI controller based upon the operating conditions of the interleaved boost converter with soft switched logic.

The paper proposes fuzzy PI controlled interleaved boost converter with a soft switched logic. The MATLAB/SIMULINK Toolbox is used for designing and simulation of the proposed controller. The proposed model is compared with conventional proportional integral controller for different loading conditions and step change in the reference voltage. For reasonable comparisons, four performance parameters are considered for the analysis such as IAE (integral of absolute error), ISE (integral of squared error), ITAE (integral of time multiplied absolute error) and settling time. The experimental verification is executed to check the suitability of the proposed fuzzy PI controlled soft switched interleaved boost converter.

The organization of the paper is given as follows:The working basis of the interleaved soft switched boost converter is explained in Section 2. The proposed Fuzzy PI controlled soft switched interleaved boost converter is described in Section 3. Section 4 explains about the simulation results. The experimental confirmation is presented in Section 5. Finally, the paper ends up with a concluding remark presented.

\section{INTERLEAVED SOFT SWITCHED BOOST CONVERTER}

The DC-DC boost converters are employed as interfacing circuit for the PV array with the Maximum Power Point Tracking (MPPT) control to provide the maximum power to the load [8]. Boost DC-DC converters have high density power, easy structure, quick transient response and constant input current 
and hence, this topology is used in different high power application such as power factor improvement, photovoltaic energy conversion systems and electric vehicles $[9,10]$. To supply high voltage output, a DC-DC boost converter is operated at maximum duty cycle, which subjects the switches to short pulse, high magnitude current that leads to Electro Magnetic Interference (EMI) problems and reverses recovery and also reduces the dynamic response for load and line variations. A high voltage output, small switching voltage loss without the maximum duty cycle can be achieved by using the converters with concept of coupled inductor circuits; however, the efficiency of the converter is reduced due to the energy loss (i.e. leakage current) in the coupled inductor. To alleviate these problems and to boost the efficiency in the boost DC-DC converter, the interleaving method is used $[11,12]$. In addition, interleaving results in reduction of current ripple through the input inductors and enhances ripple current cancellation in the output capacitor. Further, it provides improved transient response and reduced EMI. In this work, three stage interleaved soft switched boost converter is used and the voltage regulation is improved by using the fuzzy PI controller.

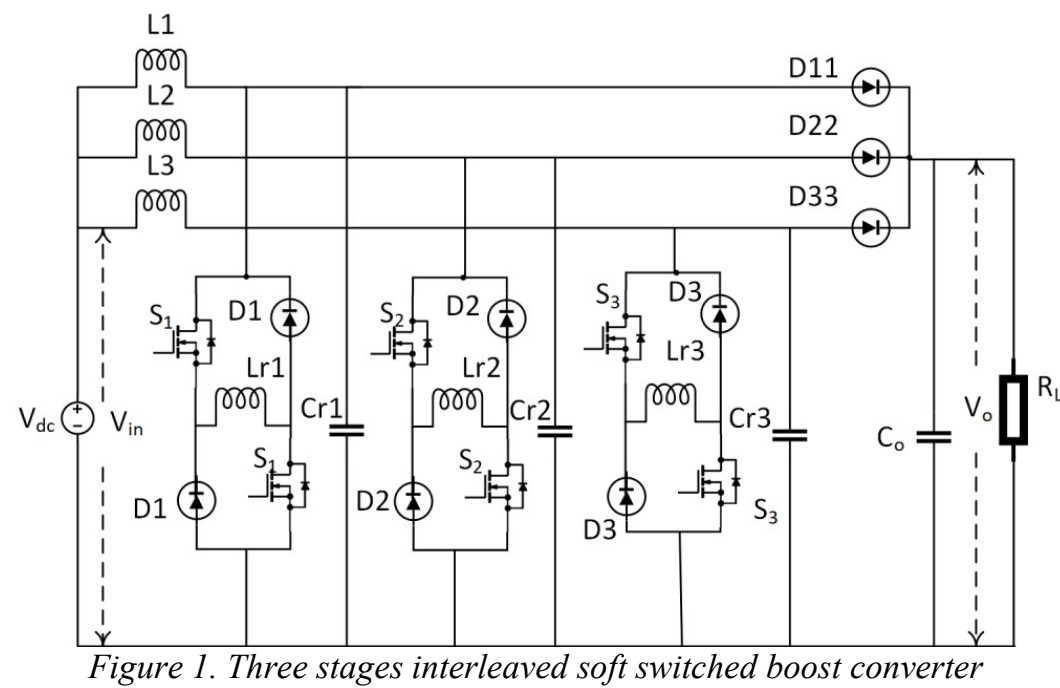

Fig. 1 shows the three stage interleaved boost converter with soft switched logic has auxiliary switches (S1, S2 and S3), resonating diodes (D1, D2 and D3), resonating capacitors (Cr1, $\mathrm{Cr} 2$ and $\mathrm{Cr} 3$ ), resonant inductors (Lr1, Lr2 and Lr3), input inductors (L1, L2, and L3), output capacitor (Co) and Load (RL). Three stages interleaving technique needs each boost converter to be connected in parallel and it is operated at the similar operating frequency, and that the switches of each boost converter is phase-shifted by $360^{\circ} / 3$. The current ripple in source, voltage ripple at output and the passive components size can be reduced due these features. The interleaving arrangements, the losses in switches are reduced drastically compared to the conventional converter $[13,14]$. Further, zero voltage and zero current switching are employed using auxiliary switching devices to further reduce the switching losses. Consequently, this three-stage interleaved soft switched boost converter has the merits of both the soft switching cells and interleaving topology.

The switching logic with the theoretically calculated current, voltage waveforms are shown in Fig. 2. In any switching cycle, switches in the two stages are tuned on and remaining stage switches in turned off conditions i.e., Switch S1 in stage 1, switch in S2 in stage two and switch S3 in stage three are switched on and off respectively. A phase shift of $120^{\circ}$ is obtained in each phase. With respect to the switching logic, the current through the inductor of each stage rises or falls linearly with a phase shift of $120^{\circ}$. As in Fig. 2, the input current ripple is reduced and hence the input current ripple frequency becomes 3 times greater than the operating frequency. 


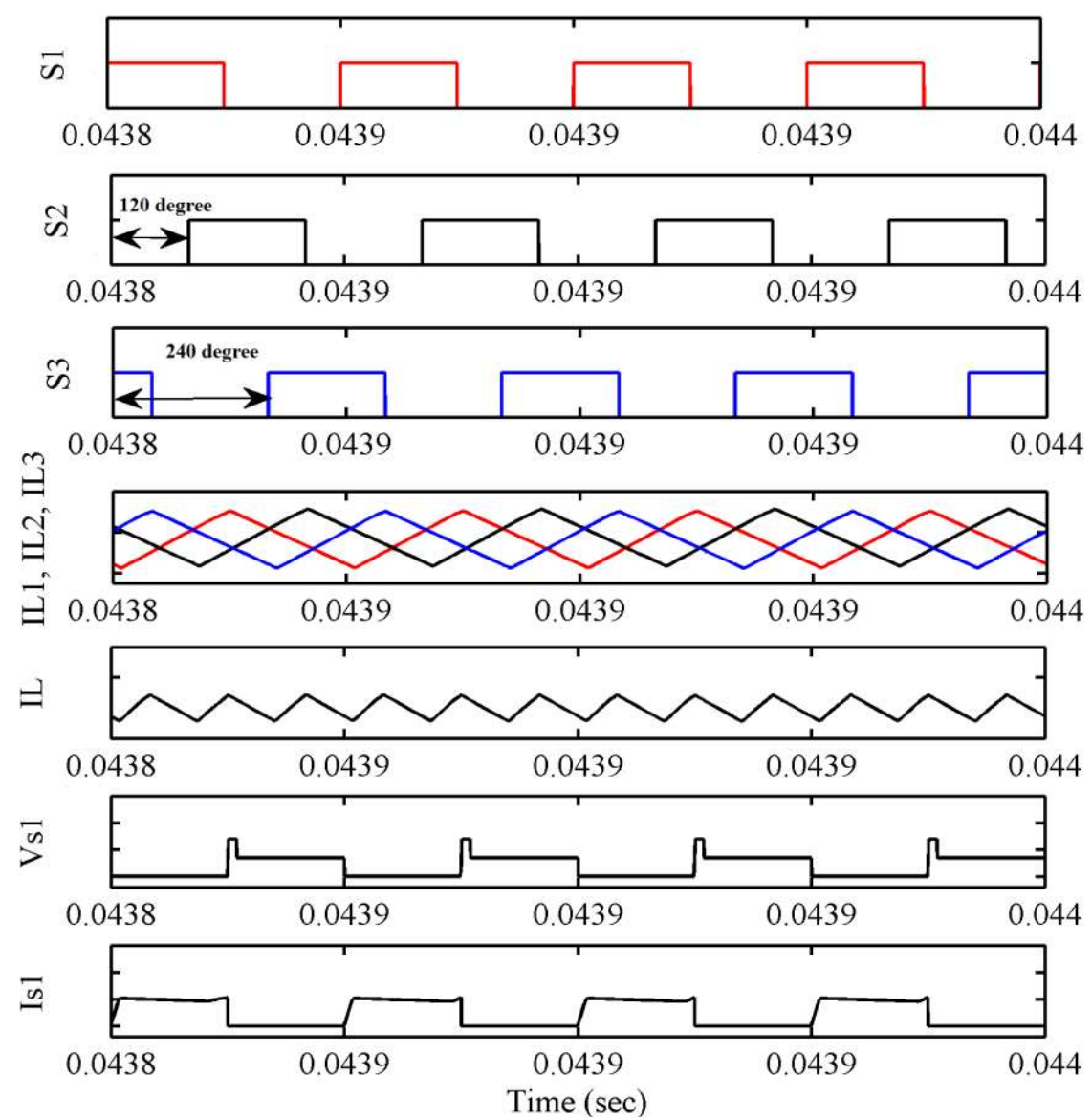

Figure 2. Switching logic of three stages interleaved soft switched boost converter

\section{FUZZY PI CONTROLLED INTERLEAVED BOOST CONVERTER WITH SOFT SWITCHED LOGIC}

The block diagram of fuzzy PI controlled interleaved boost converter with the soft switched logic is shown in Fig. 3(a). The actual voltage at the output terminal is measured by using voltage sensor and compared with the reference voltage input. The output of the comparator is being processed via fuzzy PI controller for generating control signal for the next stage. The control signal is compared with phase shifted saw tooth wave form for generating gating pulse for the interleaved soft switched boost converter. The gate pulses are given to turn on or turn off the switching elements in the converter and thereby, it controls the output voltage of the interleaved boost converter with the soft switched logic. Fig. 3(b) shows the simulation model of the fuzzy PI controlled interleaved boost converter with soft switched logic in MATLAB/Simulink toolbox. 


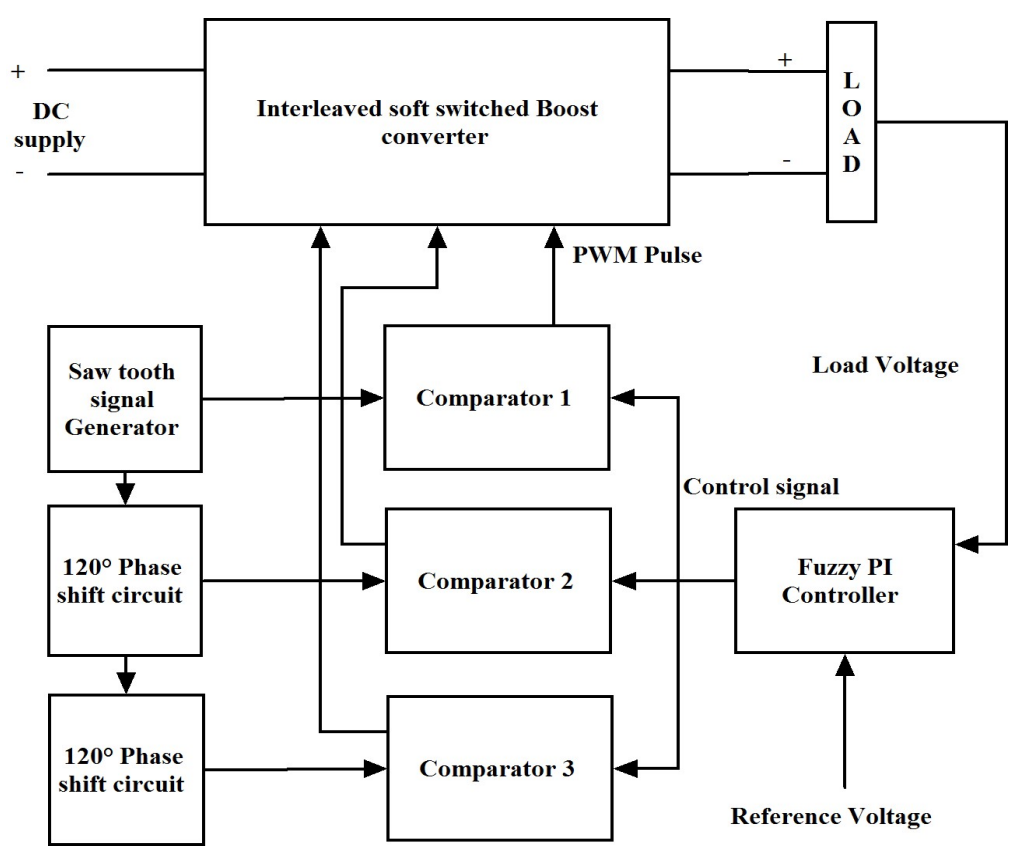

(a)

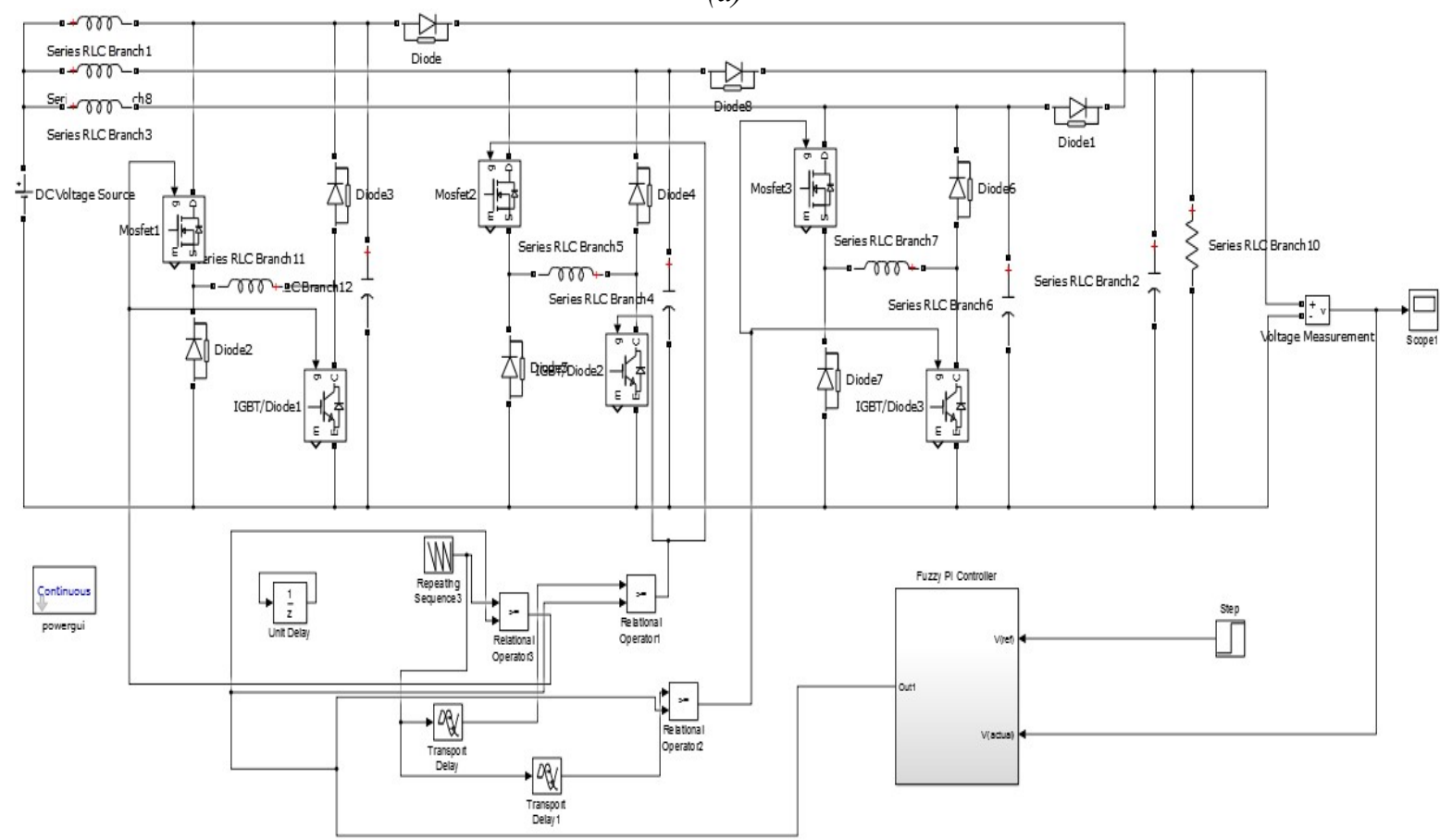

(b)

Figure3.(a) Fuzzy PI controlled interleaved boost converter with soft switched logic, (b) Simulink model of Fuzzy PI controlled interleaved soft switched Boost Converter

\subsection{Fuzzy online tuned PI Controller}

The block diagram for obtaining the variable gain using fuzzy online tuned PI controller is depicted in the Fig. 4. In online mode, all working conditions are satisfied by employing fuzzy logic control. 


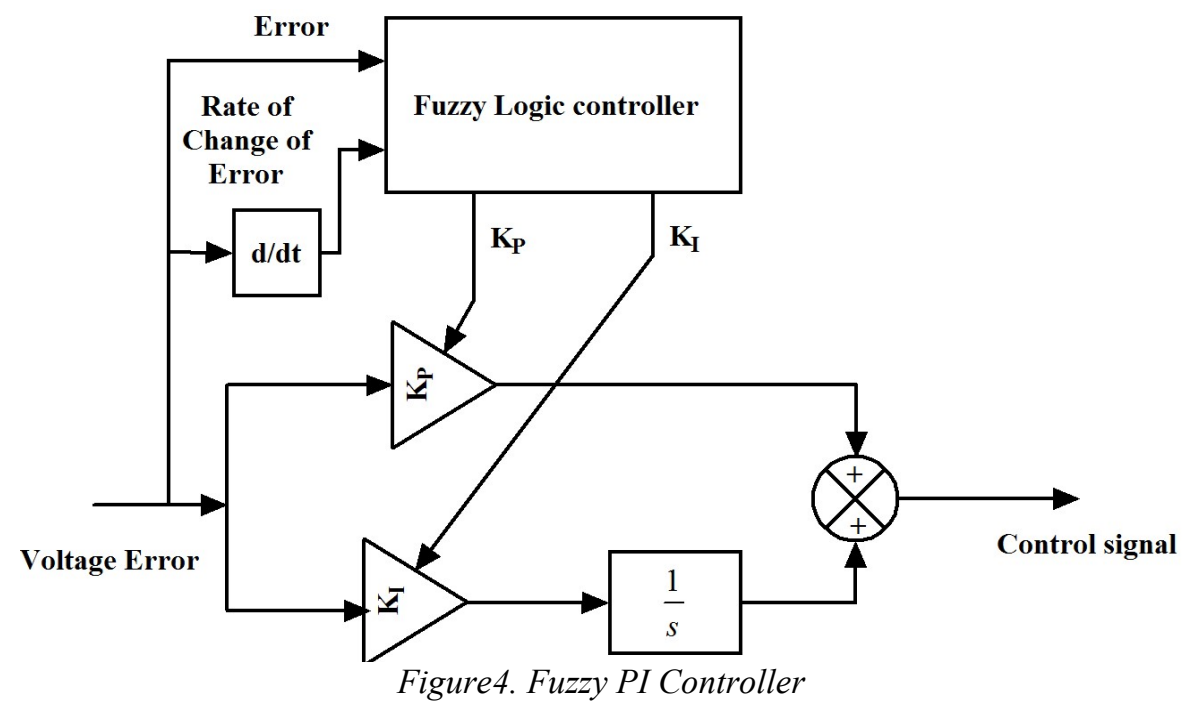

The Mamdani inference system is adapted for the model fuzzy logic controller. The fundamental blocks of the controller using fuzzy logic depicted in Fig. 5. The two inputs are voltage error and the differentiation of voltage error and two output variables are $\left(K_{P}\right.$ and $\left.K_{I}\right)$. Each input has been distributed with five bell shaped Gaussian distribution curve and each output has been scattered with same number of Gaussian norms of membership function.

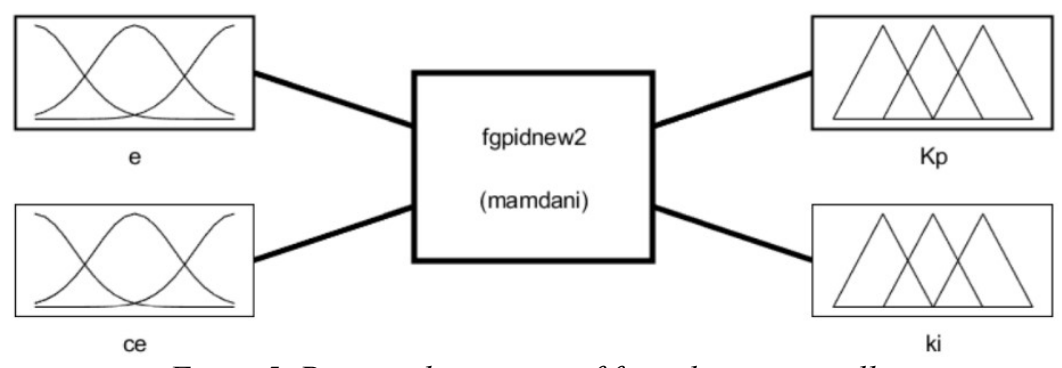

Figure5. Proposed structure of fuzzy logic controller

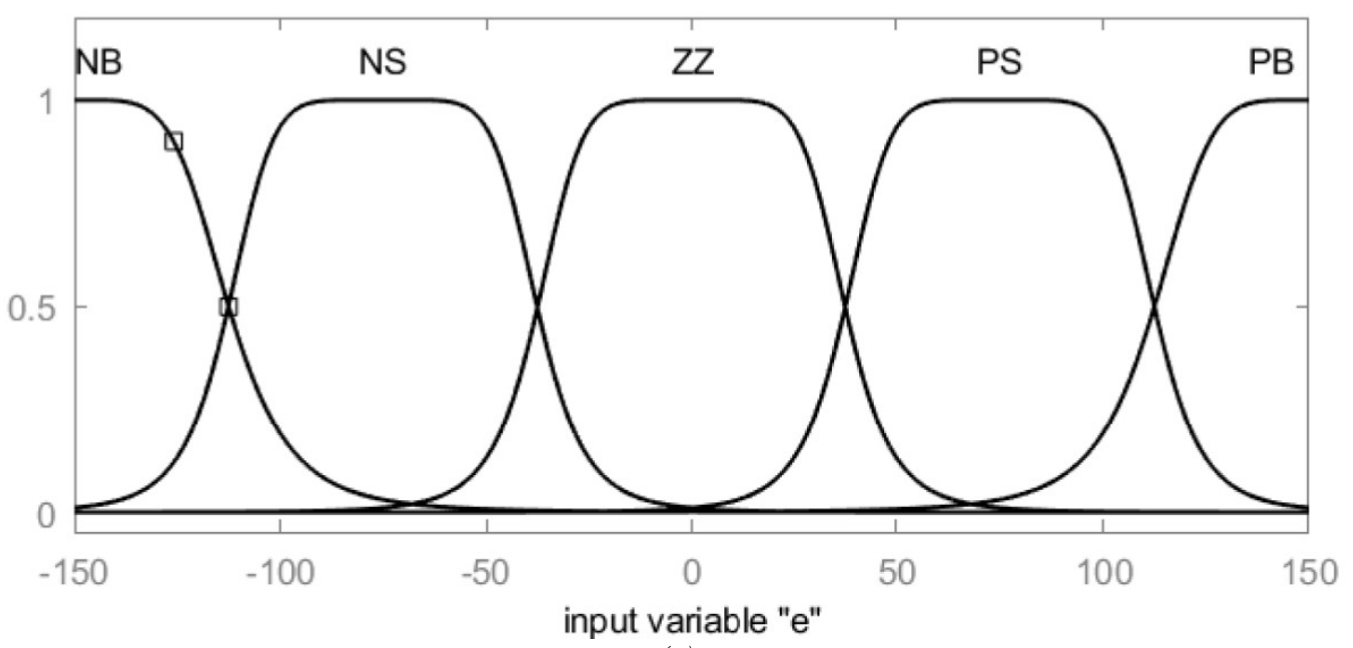

(a) 


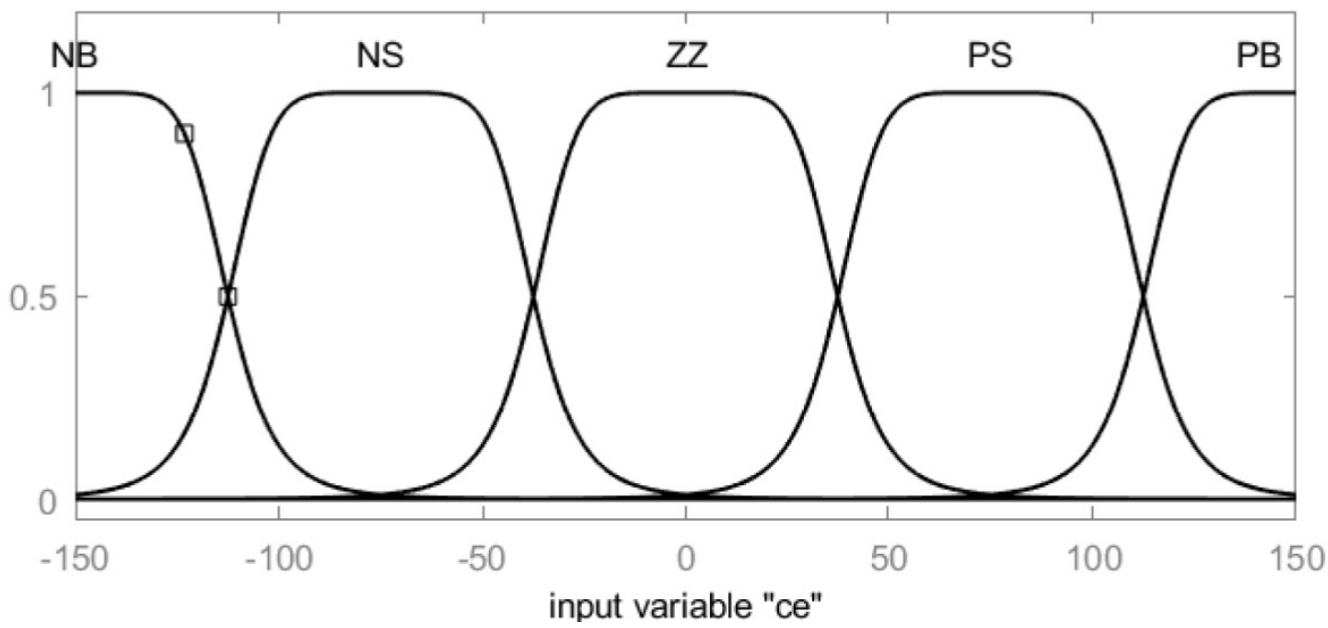

(b)

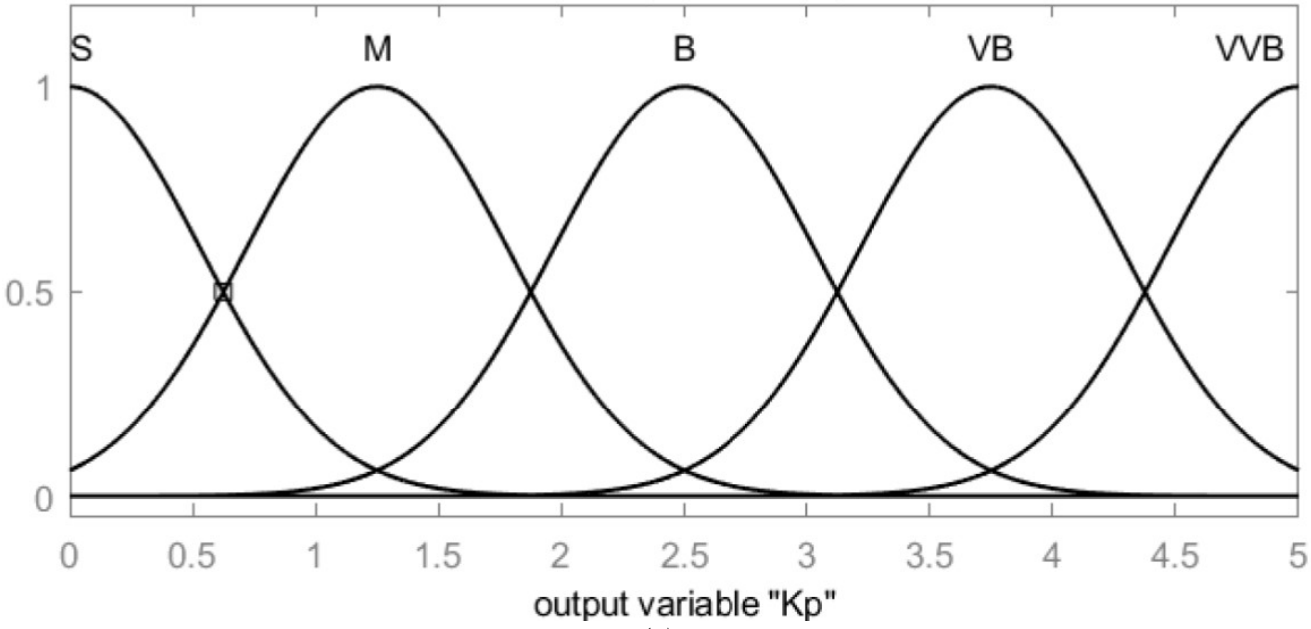

(c)

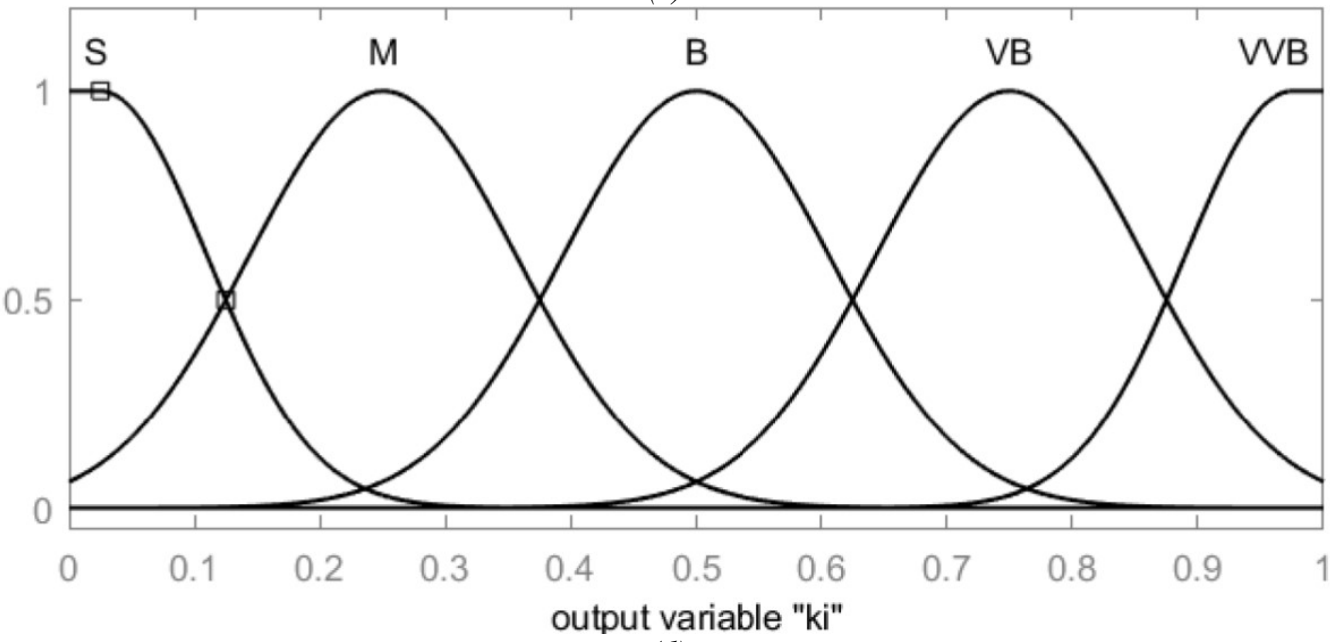

(d)

Figure 6.(a) Input membership functions distributed in voltage error, (b) input membership functions distributed in rate of change of voltage error, (c) output membership functions distributed in proportional gain $\left(K_{P}\right)$, (d) output membership functions distributed in integral gain $\left(K_{I}\right)$.

The Fig. 6(a,b) shows the input membership function distribution for the proposed controller. Eq. (1) depicts the membership function for universal bell shape curve.

$$
f(x ; a, b, c)=1 /\left(1+|(x-c) / a|^{\wedge} 2 b\right)
$$


The half width is represented by the parameter ' $a$ ', the slopes at the intersecting points are controlled by the parameter ' $b$ ' and the each membership function centre is defined by the variable ' $c$ ' ; these three parameters are required for determining the universal bell shaped function. The input range of error in voltage varies from -150 to 150 , and differentiation of voltage error varies from -150 to 150 and five membership functions denoted by PB (Positive-Big), PS (Positive-Small), ZZ (Zero), NS (Negative-Small), and NB (Negative-Big), respectively.

Five Gaussian norms functions are used to distribute the proportional gain and integral gain of the PI controller in the output of the fuzzy inference system and their distributions are shown in Fig. 6(c,d). Eq. (2) shows the generalized Gaussian function as follows:

$$
f(x ; \sigma, c)=e^{\frac{-(x-c)^{2}}{2 \sigma^{2}}}
$$

Where, $c$ denotes the center and $\sigma$ represents width of the membership function. The Very-Very Big (VVB), Very Big (VB), Big (B), Medium (M), and Small (S) represent the Gaussian membership functions distribution of output of the fuzzy inference system. The minimum and maximum gain of proportional action varies from 0 to 5 and gain of integral action range from 0 to 1 . Hence a total of twenty rules are modeled in the fuzzy inference system for fuzzy online tuned PI controller and a set of fuzzy rules are described in Eq. (3),

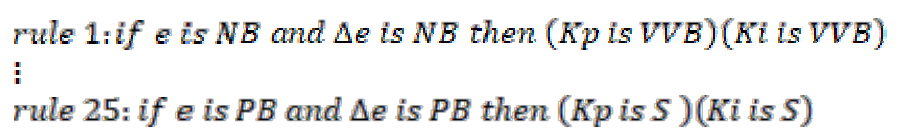

Table 1. Rule base for fuzzy online tuner

\begin{tabular}{|c|c|c|c|c|c|c|c|c|c|c|c|c|c|}
\hline \multirow{7}{*}{ 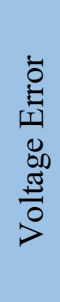 } & \multicolumn{6}{|c|}{ Differentiation of voltage error } & \multirow{7}{*}{ 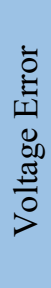 } & \multicolumn{6}{|c|}{ Differentiation of voltage error } \\
\hline & $\mathrm{K}_{\mathrm{P}}$ & NB & NS & $\mathrm{Z}$ & PS & PB & & $\mathrm{K}_{\mathrm{I}}$ & NB & NS & $\mathrm{Z}$ & PS & PB \\
\hline & NB & VVB & VB & VB & B & B & & NB & VVB & VVB & B & $\bar{M}$ & M \\
\hline & NS & VVB & VB & VB & B & B & & NS & VB & VB & B & $\bar{M}$ & $\mathrm{M}$ \\
\hline & Z & VB & VB & $\mathrm{M}$ & $\mathrm{M}$ & $\mathrm{M}$ & & Z & B & B & $\mathrm{S}$ & $\mathrm{S}$ & $\mathrm{S}$ \\
\hline & PS & $\mathrm{M}$ & $\mathrm{M}$ & $\mathrm{M}$ & $\mathrm{S}$ & $\mathrm{S}$ & & PS & $\mathrm{M}$ & $\mathrm{M}$ & $\mathrm{S}$ & $\mathrm{S}$ & $\mathrm{S}$ \\
\hline & PB & $\mathrm{M}$ & $\mathrm{M}$ & $\mathrm{M}$ & $\mathrm{S}$ & $\mathrm{S}$ & & $\mathrm{PB}$ & $\mathrm{M}$ & M & $\mathrm{S}$ & $\mathrm{S}$ & $\mathrm{S}$ \\
\hline
\end{tabular}

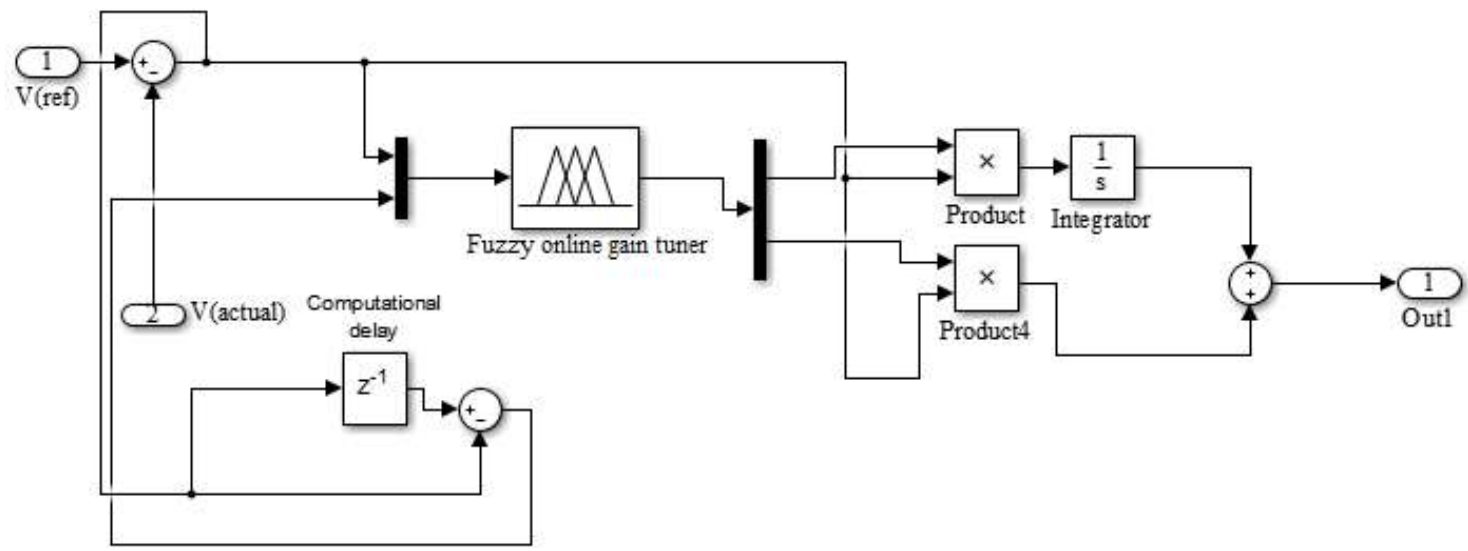

Figure 7. Simulink model of fuzzy PI controller 
Table 1 shows the overall rule base for fuzzy. The working of proportional gain fuzzy rule for three regions are as follows, if the error and rate of change of error of the system is in region of negative big to zero then proportional gain should be in the region of very-very big to very big region (Highlighted in yellow colour) to bring the system response nearer to reference command input. If error and rate of change error is in region of positive small to positive big (Highlighted in blue colour) then proportional gain should be in small region to reduce the overshot of the system and bring the system response nearer to reference command input. If error is in region of positive small to positive big and rate of change error is in region of negative big to zero region (Highlighted in green colour) then proportional gain should be in medium region to maintain the system response nearer to reference command input.

The working of integral gain fuzzy rule for three regions are as follows, if the error and rate of change of error of the system is in region of negative big to zero then integral gain should be in the region of very-very big to big region (Highlighted in yellow colour) to reduce the system negative error nearer to zero. If error and rate of change error is in region of zero to positive big (Highlighted in blue colour) then integral gain should be in small region to reduce positive system error nearer to zero. If error is in region of positive small to positive big and rate of change error is in region of negative big to negative small region and vice versa (Highlighted in green colour) then integral gain should be in medium region to maintain the system error nearer to zero.

The fuzzy inference system uses the concept of area under center of curve and this technique known as method of centroid defuzzification. Centroid defuzzification method is more frequently used method in fuzzy inference system. It is described by the equation (4) as,

$$
\operatorname{gain}_{k p p_{k} \mathrm{k}_{2} \text { kd } d \text { and keo }}=\frac{\int \mu A(x) x d x}{\int \mu A(x) d x}
$$

The output provided by the fuzzy logic controller is multiplied with proportional and integral term of the PI controller and hence produces the manipulating signal to the system. Fig. 7 depicted the simulink model of the proposed fuzzy PI voltage controller.

\section{VERIFICATION OF RESULTS BY SIMULATION}

For verifying the effectiveness of the proposed fuzzy PI controller, the response of the interleaved soft switched boost converter has been analyzed with different loading conditions and step change in reference voltage with proposed fuzzy PI controller and the PI controller. The conventional PI controller is tuned using damped oscillation method and obtained value for the proportional gain $\left(\mathrm{K}_{\mathrm{P}}\right)$ and integral gain $\left(\mathrm{K}_{\mathrm{I}}\right)$ are 3.52 and 0.77 respectively. The time varying voltage response of the interleaved soft switched boost converter and performance parameter such IAE, ISE, ITAE and settling time has been calculated and analyzed for the above controllers. Specification for interleaved soft switched boost converter is shown in Table 2 .

Table2. Parameters of the interleaved boost converter with soft switched logic

\begin{tabular}{lll}
\hline S.No & Description & Values \\
\hline 1 & Output Power & 250 watts \\
2 & Input voltage $\left(\mathrm{V}_{\mathrm{in}}=\mathrm{V}_{\mathrm{dc}}\right)$ & $42 \mathrm{Volts}$ \\
3 & Switching Frequency $\left(\mathrm{f}_{\mathrm{sw}}\right)$ & $20 \mathrm{kHz}$ \\
4 & Input Inductor $\left(\mathrm{L}_{1}=\mathrm{L}_{2}=\mathrm{L}_{3}\right)$ & $500 \mu \mathrm{H}$ \\
5 & Resonant inductor $\left(\mathrm{L}_{\mathrm{r} 1}=\mathrm{L}_{\mathrm{r} 2}=\mathrm{L}_{\mathrm{r} 3}\right)$ & $40 \mu \mathrm{H}$ \\
6 & Resonant Capacitor $\left(\mathrm{C}_{\mathrm{r} 1}=\mathrm{C}_{\mathrm{r} 2}=\mathrm{C}_{\mathrm{r} 3}\right)$ & $20 \mathrm{nF}$ \\
7 & Output Capacitor $\left(\mathrm{C}_{\mathrm{o}}\right)$ & $2200 \mu \mathrm{F}$ \\
8 & Load Resistance $\left(\mathrm{R}_{\mathrm{L}}\right)$ & $200 \Omega, 100 \Omega, 20 \Omega$ \\
9 & Output voltage $\left(\mathrm{V}_{\mathrm{o}}\right)$ & $20 \sim 150$ volts \\
\hline
\end{tabular}



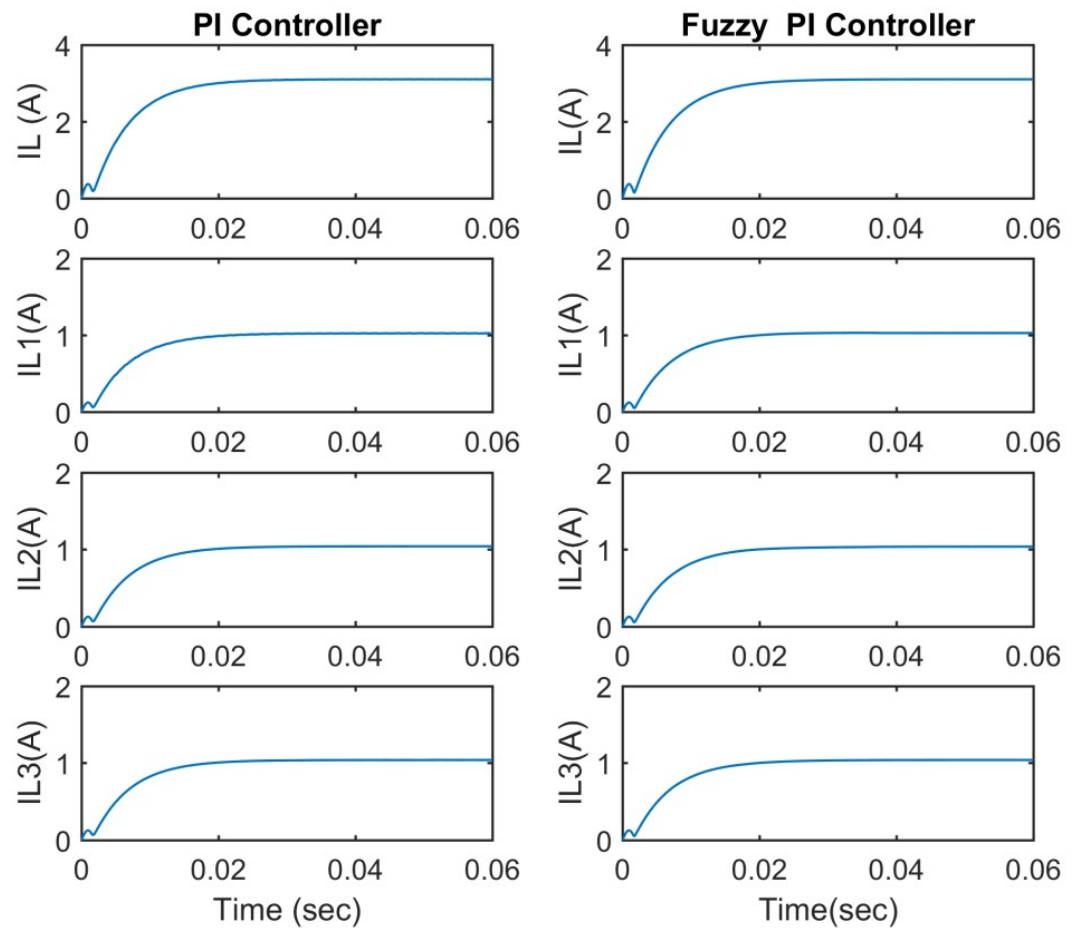

(a)
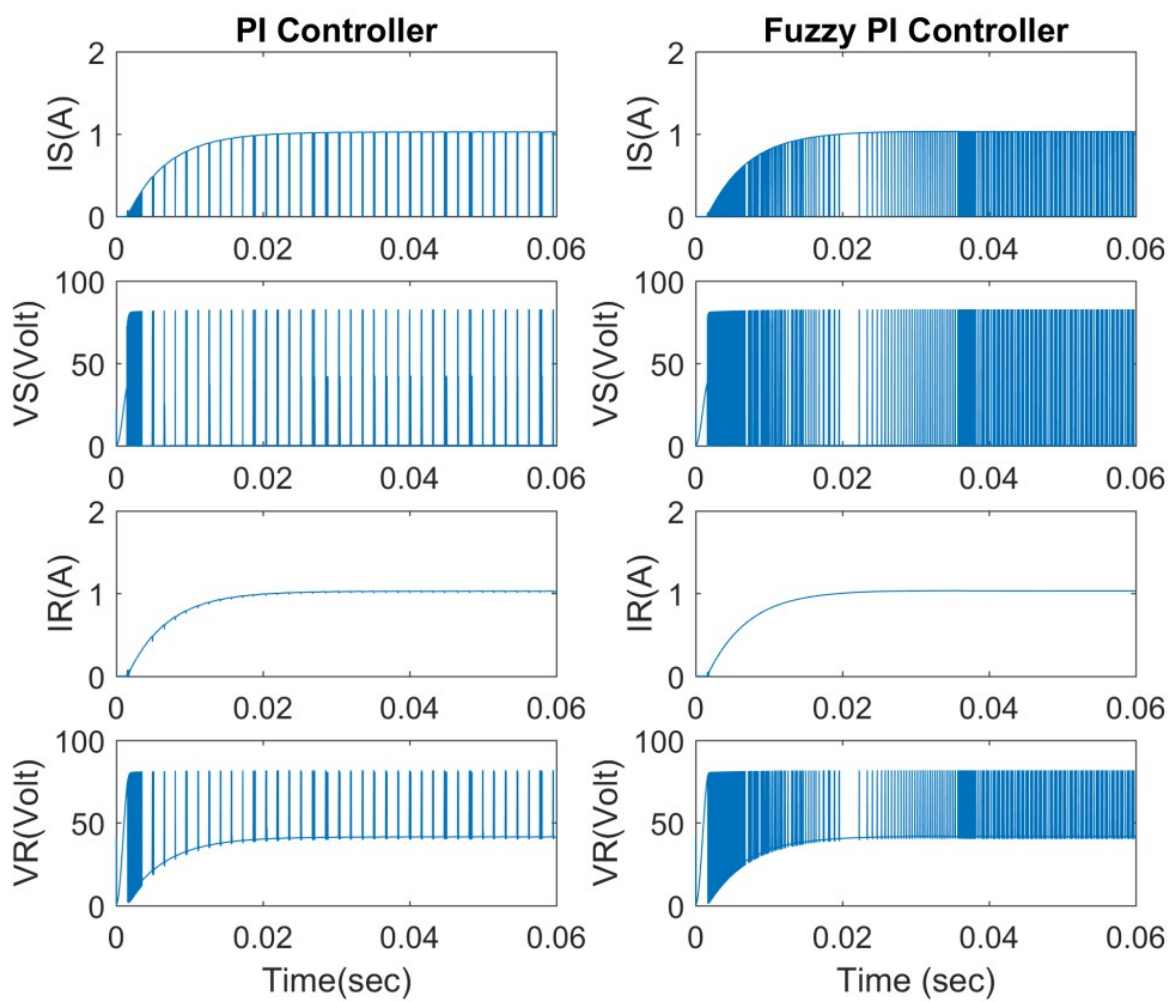

(b) 

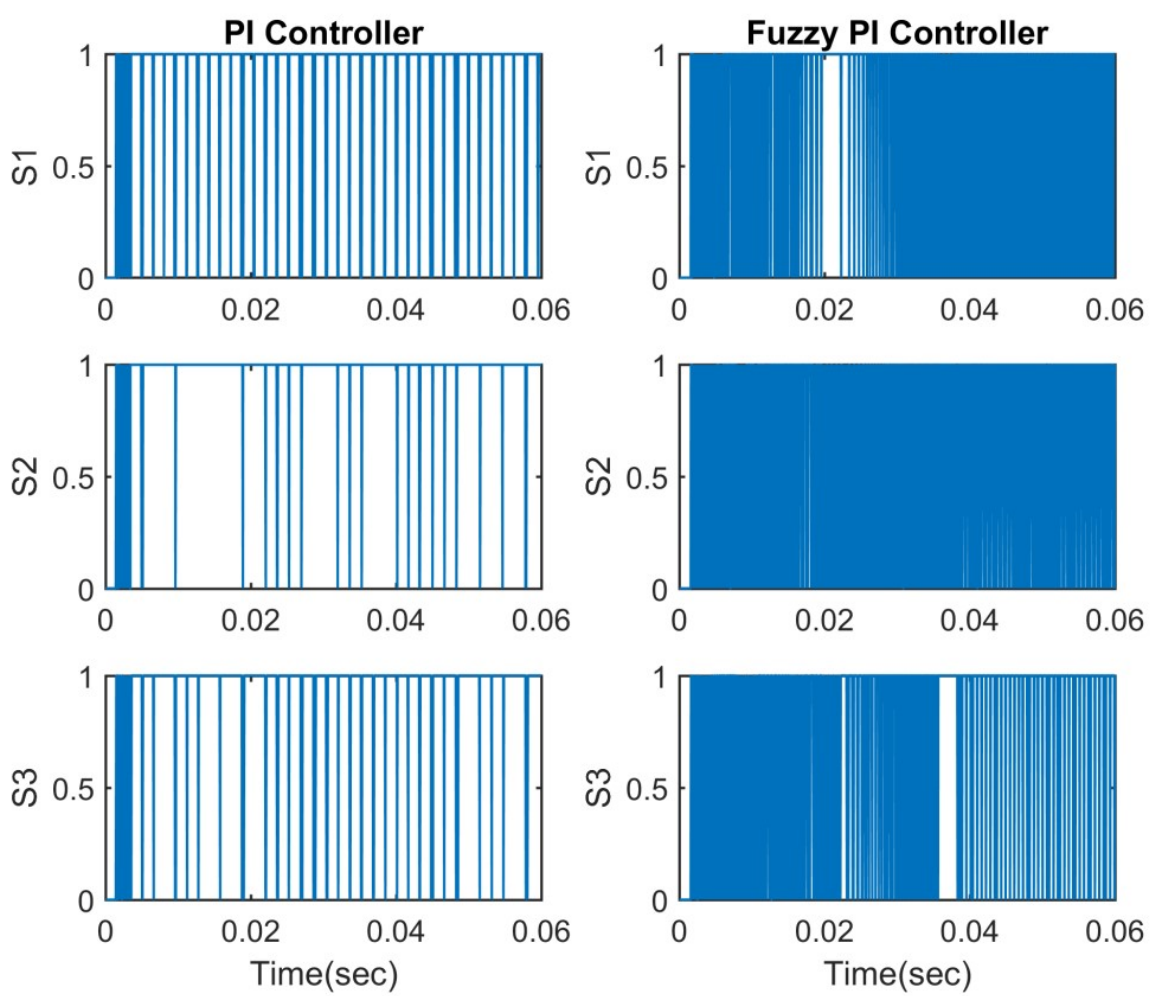

(c)

Figure 8. (a)Source current and inductor current in the each stage of ISSBC, (b) Switching current, voltage and resonant current and voltage,(c) switching pulse for $S_{1}, S_{2}$ and $S_{3}$.

Fig. 8(a) shows the wave form of source current, inductor current in each stage of the interleaved boost converter with soft switched logic. Fig. 8(b) shows the switching current with switching voltage of the main switch, resonant voltage and resonant current across and through the resonant circuit. Fig. 8(c) shows the switching pulse for S1, S2 and S3.

The interleaved soft switched boost converter is operated with constant load condition $\left(\mathrm{R}_{\mathrm{L}}=20 \mathrm{ohms}\right)$ and parameters regarding the performance are measured and analyzed for proposed controller and the PI controller. The voltage and current characteristics of the interleaved boost converter with soft switched logic with constant load condition with resistive load of $20 \mathrm{ohms}$ is shown in the Fig. 9 and their equivalent performance parameters are depicted in Table 3.

From the voltage response curve (Fig. 9) and Table 3, it is observed that proposed controller i.e., fuzzy PI voltage controller has IAE of 2, ISE of 5, ITAE of 3 and settling time of $4 \mathrm{~m}$-sec but these performance parameters are not in favour for the PI controller. Therefore, it can be proved that the proposed fuzzy PI controller outperforms than classical PI controller. 

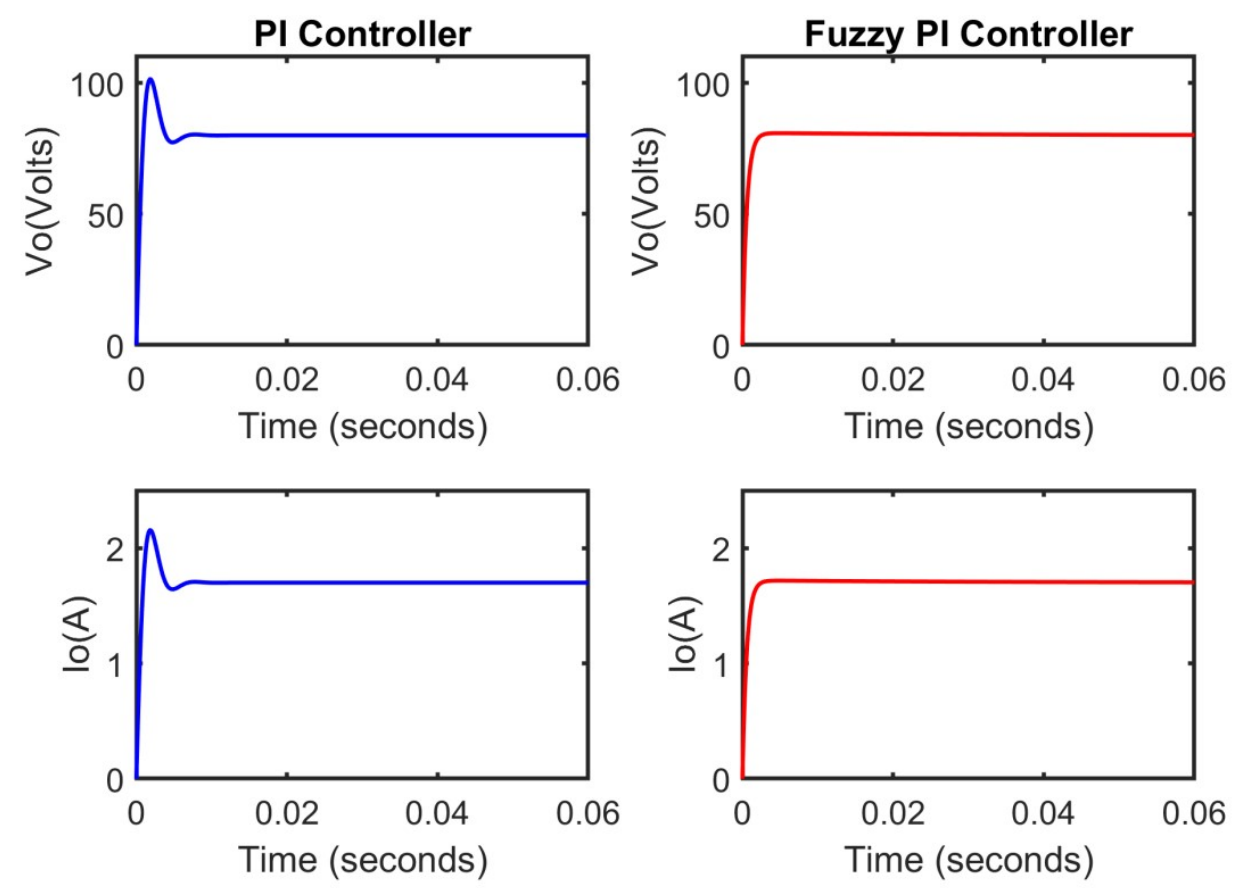

Figure9. Voltage and current response of converter for constant load conditions.

Table 3. Performance parameters for constant Load Condition

\begin{tabular}{ccccc}
\hline \multirow{2}{*}{ Controller } & \multicolumn{4}{c}{ Performance parameters } \\
\cline { 2 - 5 } & IAE & ISE & ITAE & Settling time $(\mathrm{ms})$ \\
\hline PI Controller & 15 & 33 & 10 & 6 \\
Fuzzy PI Controller & 2 & 5 & 3 & 4 \\
\hline
\end{tabular}

The interleaved soft switched boost converter is operated with two different loading conditions for verifying the suitability of the proposed fuzzy PI controller under sudden changing load conditions. In this examination, two conditions are considered. Case-A, load is set to $100 \mathrm{ohms}$ and input is set to 42 volts. Case-B, load is set to $200 \mathrm{ohms}$ and input is set to 42 volts. Figure 10 shows the response of voltage and current in the interleaved soft switched boost converter. The performance parameters for the two loading conditions are shown in the Table 4. Note that time units are in milliseconds in the tables.

Table 4. Performance parameters for different load conditions

\begin{tabular}{lllllllll}
\hline \multirow{2}{*}{ Controller } & \multicolumn{7}{c}{ Control system performance parameters } \\
\cline { 2 - 10 } & \multicolumn{2}{c}{ IAE } & \multicolumn{2}{c}{ ISE } & \multicolumn{2}{c}{ ITAE } & \multicolumn{2}{c}{ Settling time (ms) } \\
\cline { 2 - 10 } & Case-A & Case- B & Case- A & Case-B & Case-A & Case-B & Case-A & Case-B \\
\hline PI Controller & 11.4 & 12 & 15.5 & 14.5 & 13.2 & 13.2 & 6 & 6 \\
Fuzzy PI Controller & 3.2 & 3.1 & 2.5 & 2.4 & 2.3 & 2.2 & 5 & 4 \\
\hline
\end{tabular}



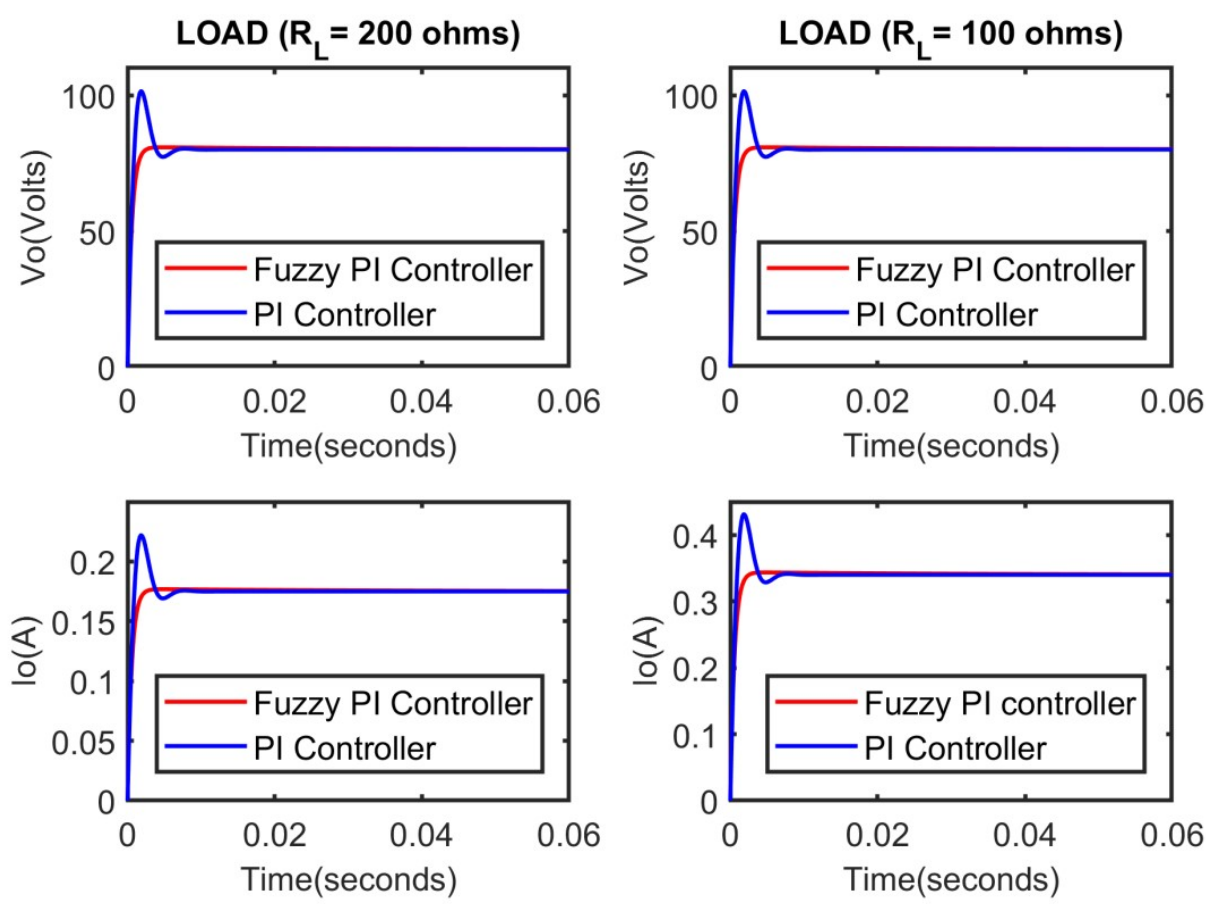

Figure 10. Voltage and current response of converter for different loading conditions.

The voltage response curves (Fig. 10) and Table 4 results, illustrate that the proposed fuzzy PI controller has enhanced control system performance parameter than traditional PI controller. With different loading conditions, all essential performance parameters are in favours only for the proposed fuzzy PI controller.

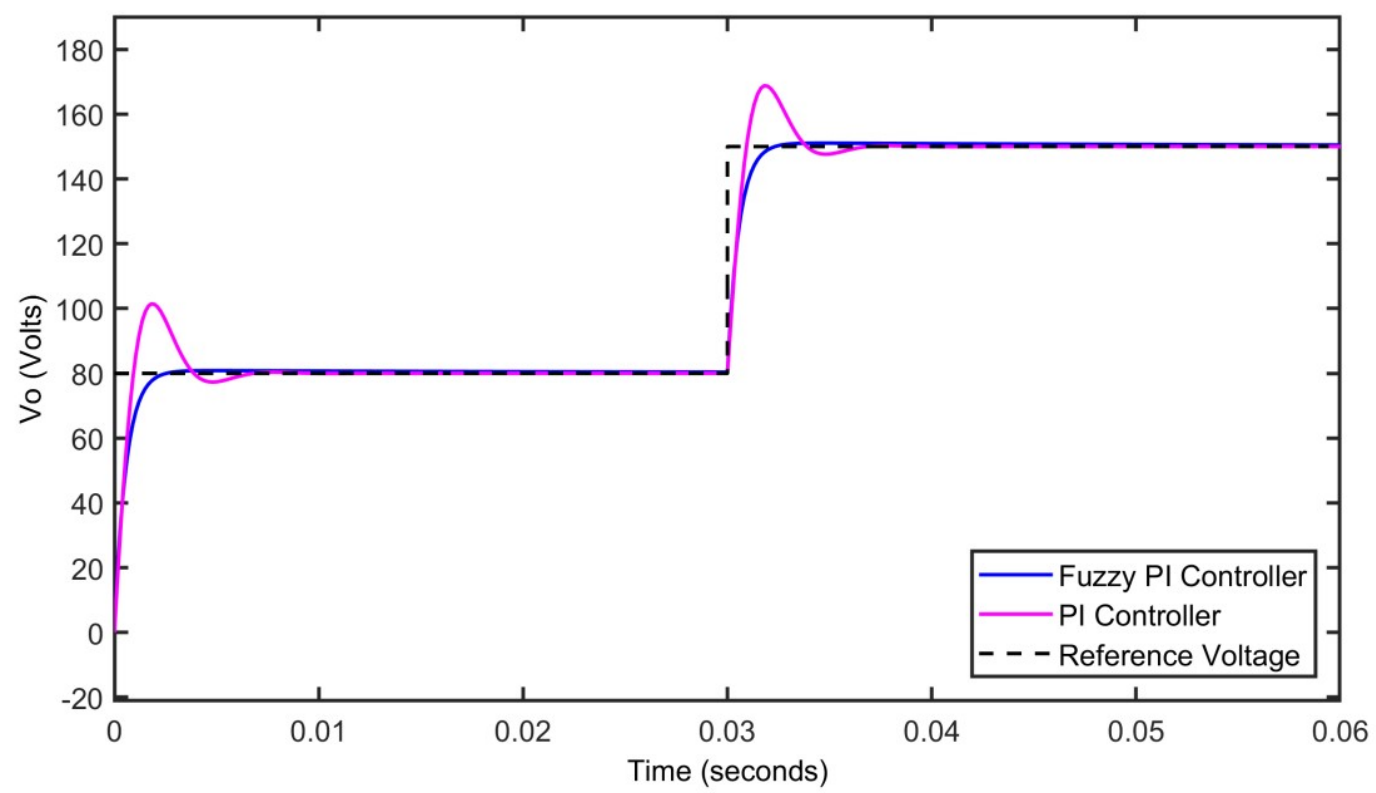

Figure11. Voltage response of converter for reference voltage change in condition.

Process industries require variable voltage for some specific operation. For checking the suitability and the effectiveness of the proposed fuzzy PI controller, sudden changing reference voltage conditions of the proposed fuzzy PI controlled and PI controlled soft switched interleaved boost converter is simulated. In this examination, the reference voltage is varied from 80 volts to 150 volts at $0.03 \mathrm{sec}$. Fig. 11 shows the response of voltage variation for the interleaved soft switched boost converter for this conditions. Table 5 shows the control system performance parameter for the system under this condition. 
Table 5. Performance parameters for reference voltage change in condition

\begin{tabular}{lllll}
\hline \multirow{2}{*}{ Controller } & \multicolumn{4}{c}{ Control system performance parameters } \\
\cline { 2 - 5 } & IAE & ISE & ITAE & Settling time $(\mathrm{ms})$ \\
\hline PI Controller & 12.2 & 14.1 & 13.8 & 36 \\
Fuzzy PI Controller & 3.4 & 2.1 & 2.4 & 33 \\
\hline
\end{tabular}

From the voltage response curves (Fig. 11) and Table 5, the voltage of the interleaved soft switched boost converter shows a quick settling time, i.e., $33 \mathrm{~ms}$ only with the proposed fuzzy PI controller but PI controller takes more time to accomplish the set reference voltage and still the remaining parameters are also favouring the proposed controller. The objective of the developed proposed fuzzy PI controller is reducing the steady state error, reduce the overshoot and make the system response quick by automatically tuning the gain of the PI controller using Fuzzy logic control based on the operating conditions of the system and rule base created in the fuzzy inference system. Due to that, it reduces the index parameter i.e., IAE, ISE and ITAE automatically. That is why these parameters are very low for the proposed fuzzy PI controller than conventional PI controller in all tested conditions.

\section{EXPERIMENTAL VERIFICATION OF PROPOSED CONTROL SYSTEM}

The experimental verification is explained in this section to verify suitability and effectiveness of the proposed fuzzy PI controlled soft switched three stages interleaved boost converter. The hardware setup consists of three stage power circuit: DSP processor for implementing fuzzy PI control and generating pulse, resistive load and power supply circuit. The three stage power circuit consists of three parallel boost converters with six MOSFET, six SiC diodes and inductor, resonant inductor, resonant capacitor and output capacitor. The $6 \mathrm{~N} 137$ optocoupler is used to isolate DSP processor from power circuit. TMS320LF2407A DSP Processor is used for generating the gating pulses based on control signal from the fuzzy PI control to commutate the MOSFET. Snapshot of the hardware setup is shown in Fig. 12.

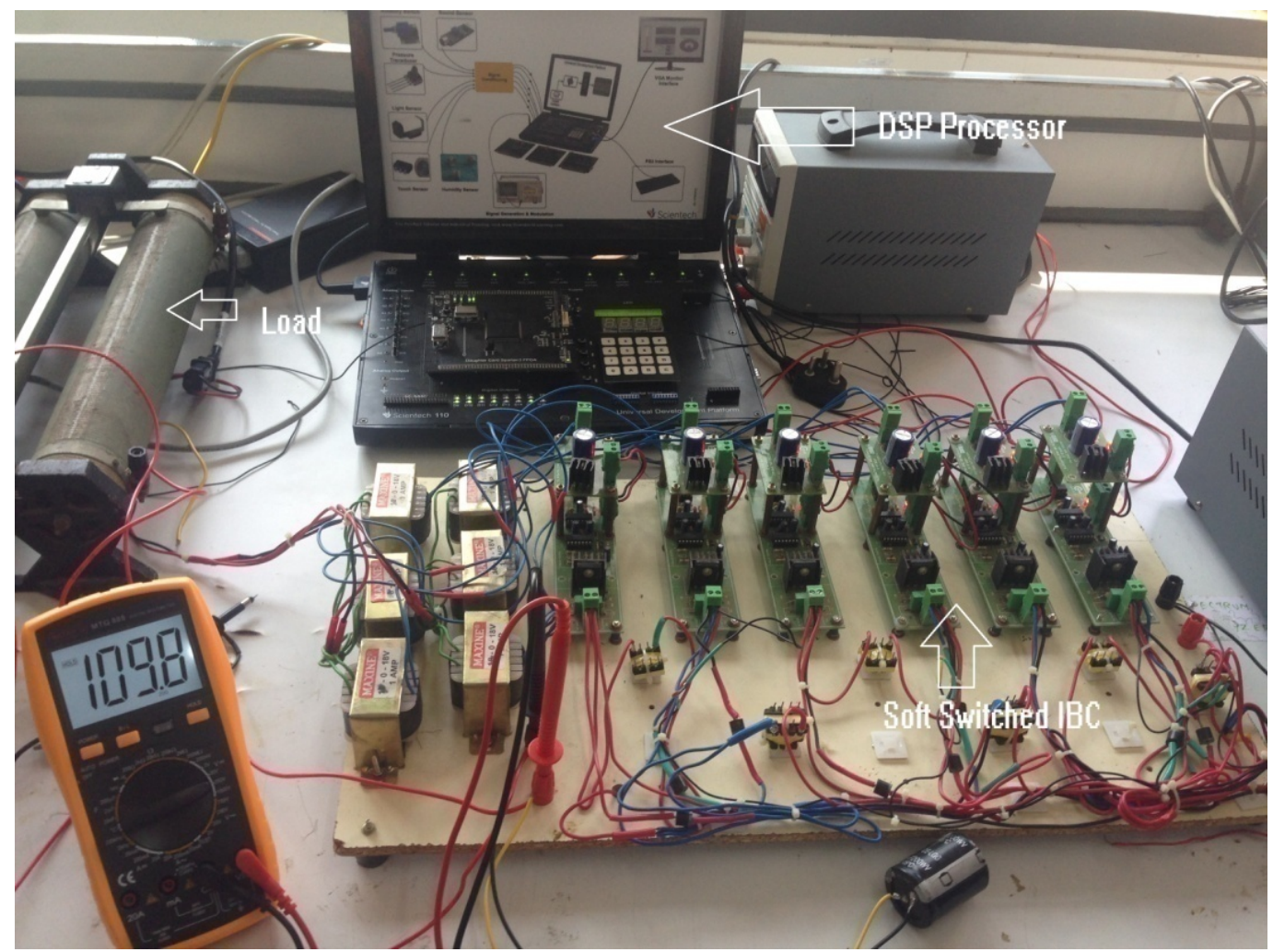

Figure12. Hardware snapshot of the fuzzy PI controlled soft switched three stages interleaved boost converter 


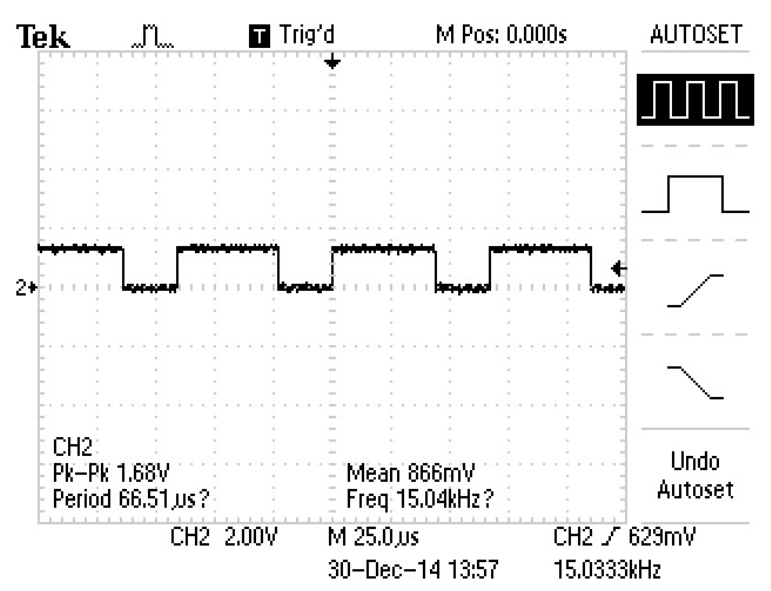

(a)

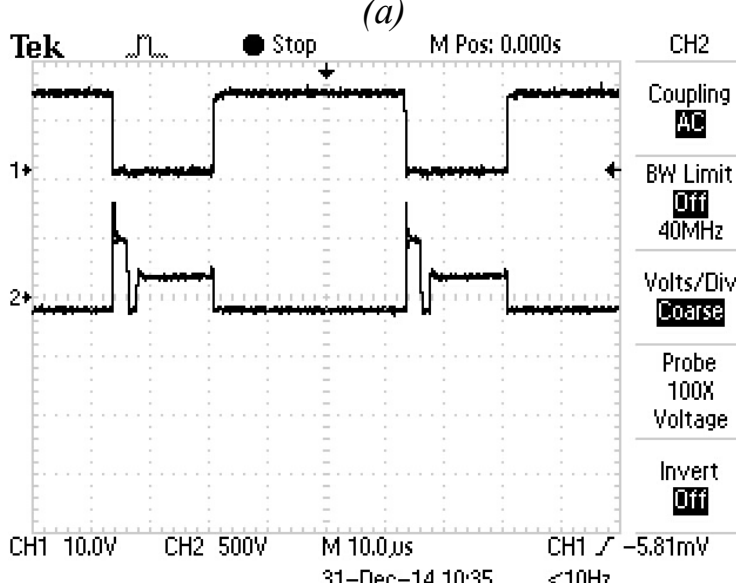

(c)

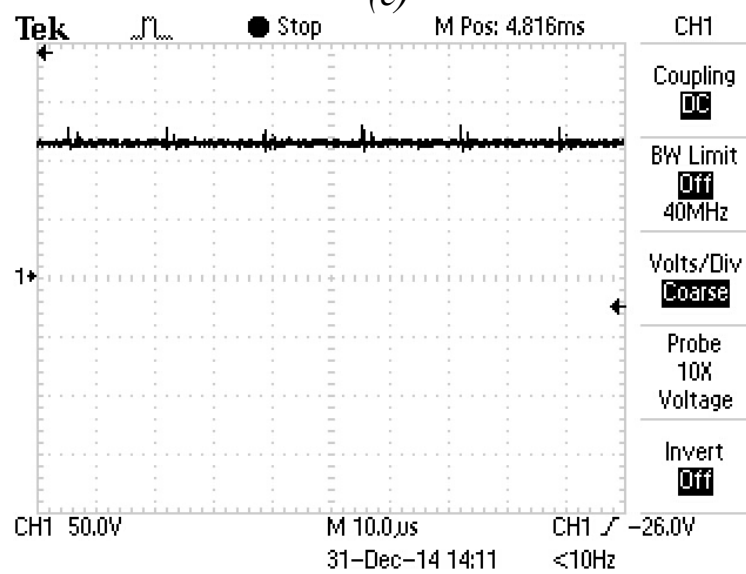

(e)

\begin{tabular}{|c|c|c|}
\hline एव Volts & \multicolumn{2}{|c|}{ 2014-12-31, 11:49 } \\
\hline & & $0.0 \mathrm{~Hz}$ \\
\hline $\mathrm{Vac}$ & V avg & V pk \\
\hline 0.6 & 109.9 & 110.5 \\
\hline $\mathrm{V} / \mathrm{Hz}$ & $\%$ RPL & CF \\
\hline DL & 0.5 & 1.01 \\
\hline
\end{tabular}

(g)

Figure13. Experimental result of fuzzy PI controlled soft switched three stages interleaved boost converter: a) Pulse for S1, b) Pulse for S2 and S3, c) Voltage across main diode 1 and resonant diode 1, d) Voltage across resonant capacitor 1 and MOSFET1, e) output voltage of converter, $f$ ) output voltage and input current of the converter, g) output voltage ripple detail, h) input current detail.

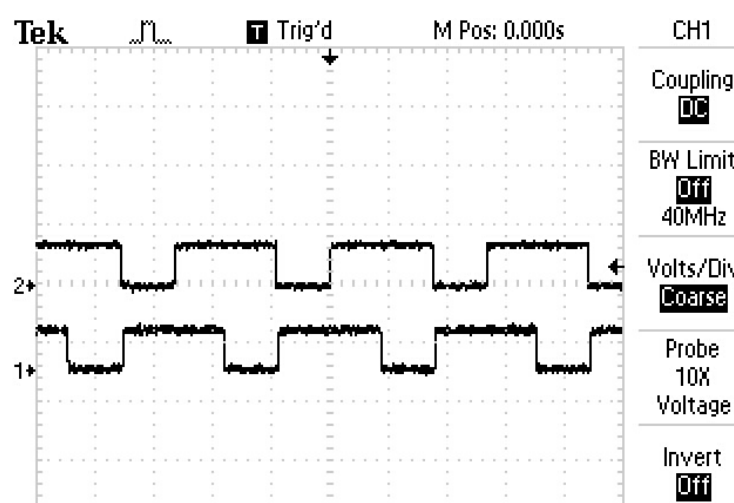
CH1 vertical position $-1,48$ divs $(-29,6 \mathrm{~W})$

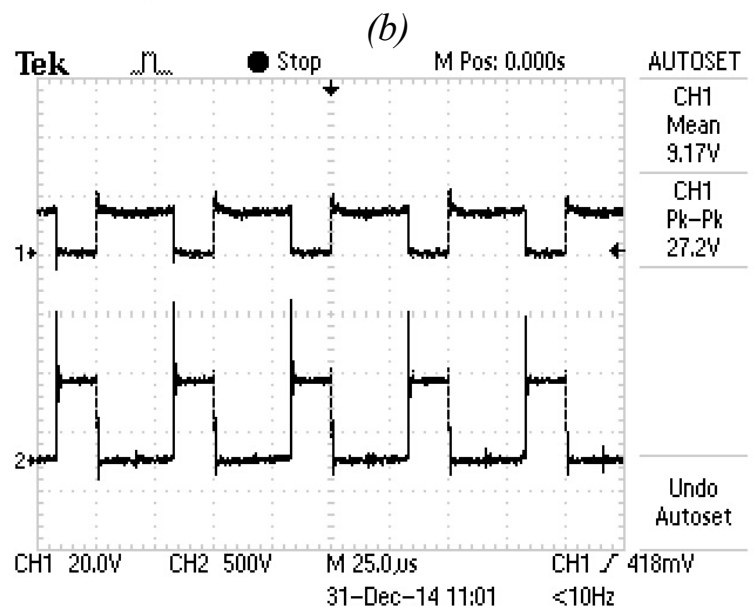

(d)

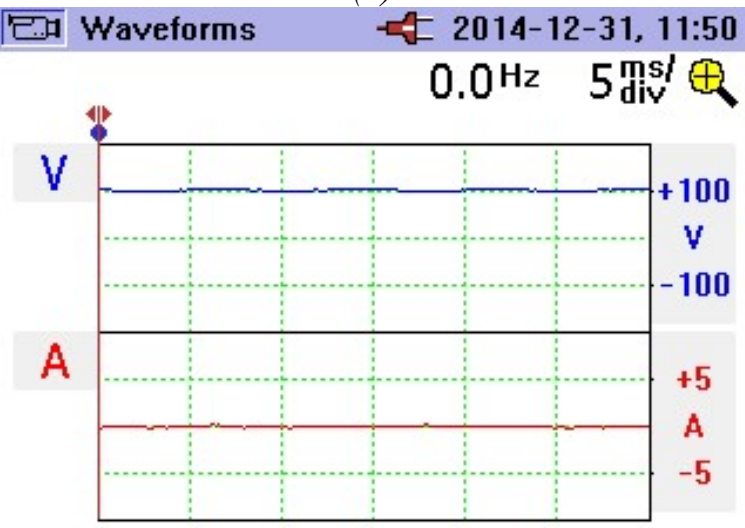

(f)

\begin{tabular}{|c|c|c|}
\hline 西 Ams & \multirow{2}{*}{\multicolumn{2}{|c|}{$\begin{array}{r}2014-12-31,12: 03 \\
0.0 \mathrm{~Hz}\end{array}$}} \\
\hline & & \\
\hline $\mathrm{A}$ ac & A avg & A pk \\
\hline 0.11 & 1.90 & 2.30 \\
\hline $\mathrm{A} / \mathrm{Hz}$ & $\%$ RPL & CF \\
\hline L & 5.01 & 1.26 \\
\hline
\end{tabular}

(h)
$\mathrm{CH} 120.0 \mathrm{~W} \quad \mathrm{CH} 22,00 \mathrm{~W} \quad \mathrm{M} 25.0 \mu \mathrm{s} \quad \mathrm{CH} 2 \mathrm{~J} 629 \mathrm{~mW}$ 
The experimental result of soft switched three stage interleaved boost converter with fuzzy PI controller is depicted in Fig. 13. By examine the experimental result and it is identical to result of simulation.

\section{CONCLUSION}

This research deals about voltage regulation of interleaved soft switched boost converter using fuzzy PI controller. A structure of the proposed fuzzy PI controlled and PI controlled soft switched interleaved boost converter has been designed and developed using MATLAB/ Simulink Toolbox. The proposed fuzzy PI controller is tested under various operating conditions of the interleaved boost converter with soft switched logic and it was compared with classical PI controller. The test result shows that all vital parameters such as IAE, ISE, ITAE and settling time are in favor for proposed fuzzy PI controller. Therefore, fuzzy PI controller is suitable voltage controller for interleaved soft switched boost converter. Digital signal processor is used for real time implementation of the fuzzy PI controller and experimental results have been compared with simulation results. Similar results were exhibits in simulation and experimentation.

\section{REFERENCES}

[1] Yao, G., Chen A., \& He, X., Soft Switching Circuit for Interleaved Boost Converters, IEEE Transactions on Power Electronics, 2007, 22(1),80-86.

[2] Li,W., \&He, X., High step up soft switching interleaved boost converters with cross winding coupled inductors and reduced auxiliary switch number, IET Power Electronics, 2009, 2(2),125-133.

[3] Park, S., Park, Y., Choi, S., Choi, W.,\& Lee, K. B., Soft Switched Interleaved Boost Converters for High Step Up and High Power Applications, IEEE Transactions on Power Electronics, 2011, 26 (10),2906-2914.

[4] Premkumar, K., \&Manikandan, B.V., Adaptive Neuro Fuzzy Inference System based speed controller for brushless DC motor, Neurocomputing, 2014, 138,260-270.

[5] Premkumar, K., \&Manikandan, B.V., Bat algorithm optimized fuzzy PD based speed controller for brushless direct current motor, Engineering Science and Technology, an International Journal, 2016, 19(2),818-840.

[6] Premkumar, K., \&Manikandan, B.V., Adaptive fuzzy logic speed controller for brushless DC motor, 2013 International Conference on Power, Energy and Control (ICPEC), Sri RangalatchumDindigul, 2013, 290295, DOI: 10.1109/ICPEC.2013.6527668.

[7] Premkumar, K., \&Manikandan, B.V., Fuzzy PID supervised online ANFIS based speed controller for brushless de motor, Neurocomputing, 2015, 157,76-90.

[8] Jung, D. Y., Ji, Y. H., Park, S. H., Jung Y. C., \& Won C. Y., Interleaved soft- switching boost converter for photovoltaic power-generation system, IEEE Transactions on Power Electronics, 2011, 26(4),1137-1145.

[9] Mishima, T., Takeuchi Y., \&Nakaoka, M., analysis, design, and performance evaluations of an edgeresonant switched capacitor cell-assisted soft-switching PWM boost DC-DC converter and its interleaved topology, IEEE Transactions on Power Electronics, 2013, 28(7), 3363-3378.

[10] Pulvirenti, F., La Scala, A., Ragonese, D., D'Souza, K., Tina G. M., \&Pennisi, S., 4-Phase interleaved boost converter with IC controller for distributed photovoltaic systems, IEEE Transactions on Circuits and Systems I: Regular Papers, 2013, 60(11), 3090-3102.

[11] Kim, D. H., ChoeG. Y., \&Lee, B. K., DCM analysis and inductance design method of interleaved boost converters, IEEE Transactions on Power Electronics, 2013, 28(10), 4700-4711.

[12] Gerber D.,\&Biela,J., Interleaving of a soft-switching boost converter operated in boundary conduction mode, IEEE Transactions on Plasma Science, 2015, 43(10), 3374-3380.

[13] E Silva Aquino, R. N. A. L., Tofoli, F. L., Praca, P. P., Oliveira,D. d. S.,\&Barreto,L. H. S. C., Soft switching high voltage gain DC-DC interleaved boost converter, IET Power Electronics, 2015, 8(1), 120129.

[14] Wu,H., Mu,T., Ge,H.,\& Xing,Y., Full-range soft switching isolated buck boost converters with integrated interleaved boost converter and phase shifted control, IEEE Transactions on Power Electronics, 2016, 31(2),987-999. 